\title{
Simultaneous Determination of Clidinium Bromide and Chlordiazepoxide in Combined Dosage Forms by High-Performance Liquid Chromatography
}

\author{
Safwan Ashour and Nuha Kattan \\ Analytical Biochemistry Laboratory, Department of Chemistry, Faculty of Science, University of Aleppo, Aleppo, Syria \\ Correspondence should be addressed to Safwan Ashour; profashour@myway.com
}

Received 13 December 2012; Accepted 23 January 2013

Academic Editor: Antonio Ruiz Medina

Copyright (C) 2013 S. Ashour and N. Kattan. This is an open access article distributed under the Creative Commons Attribution License, which permits unrestricted use, distribution, and reproduction in any medium, provided the original work is properly cited.

A sensitive and precise RP-HPLC method has been developed for the simultaneous estimation of clidinium bromide (CDB) and chlordiazepoxide $(\mathrm{CDZ})$ in pure and pharmaceutical formulations. The separation was achieved on a Nucleodur $\mathrm{C}_{8}(250 \times 4.6 \mathrm{~mm}$ i.d., $5 \mu \mathrm{m}$ particle size) column at $25^{\circ} \mathrm{C}$. $\mathrm{CH}_{3} \mathrm{CN}-\mathrm{MeOH}-\mathrm{NH}_{4} \mathrm{OAc} 0.1 \mathrm{M}(30: 40: 30 \mathrm{v} / \mathrm{v} / \mathrm{v})$ was used as the mobile phase at a flow rate of $1.0 \mathrm{~mL} \mathrm{~min}^{-1}$ and detector wavelength at $218 \mathrm{~nm}$. Almotriptan (ALT) was used as internal standard. The validation of the proposed method was carried out for linearity, accuracy, precision, LOD, LOQ, and robustness. The method showed good linearity in the ranges of $2.5-300.0$ and $3.0-500.0 \mu \mathrm{g} \mathrm{mL}^{-1}$ for CDB and CDZ, respectively. The percentage recovery obtained for CDB and CDZ was $100.40-103.38$ and $99.98-105.59 \%$, respectively. LOD and LOQ were 0.088 and $0.294 \mu \mathrm{gL}^{-1}$ for CDB and 0.121 and $0.403 \mu \mathrm{g} \mathrm{mL}^{-1}$ for CDZ, respectively. The proposed method was successfully applied to the determination of CDB and CDZ in combined dosage forms and the results tallied well with the label claim.

\section{Introduction}

Chlordiazepoxide (7-chloro- $\mathrm{N}$-methyl-5-phenyl-3H-1, 4-benzodiazepine-2-amina-4-oxide) is used as an anxiolytic, sedative, hypnotic, anticonvulsant, and/or skeletal muscle relaxant. The drug may inhibit monosynaptic and polysynaptic reflexes by acting as an inhibitory neuronal transmitter or by blocking excitatory synaptic transmission. The drug may also directly depress motor nerve and muscle function $[1$, 2]. Clidinium bromide (3-[(hydroxy-diphenylacetyl)-oxy]1-methyl-1-azoniabicylo-[2.2.2] octane bromide is an anticholinergic drug which may help symptoms of cramping and abdominal stomach pain by decreasing stomach acid and slowing the intestines. It is commonly prescribed in combination with chlordiazepoxide by the name of clidinium-c [3]. The United States Pharmacopeia (USP) stated the nonaqueous titration method for the assay of clidinium bromide and chlordiazepoxide [4]. Few methods for the determination of clidinium bromide and chlordiazepoxide in combined dosage forms including HPLC [5-7], derivative spectrophotometry $[8,9]$, spectrophotometry using multivariate calibration techniques [10], and capillary SFC [11] have been reported. Literature survey revealed that some analytical methods have been used for the individual estimation of clidinium bromide and chlordiazepoxide. Capillary electrophoresis [12] and kinetic spectrophotometric [13] methods for clidinium bromide have been described. Chlordiazepoxide has been determined either alone or with other compounds in pharmaceutical formulations using high-performance liquid chromatography [14-23], first-derivative spectrophotometry [17], spectrophotometry [23, 24], HPTLC [23, 25], voltammetry [26], and flow-injection potentiometry [27]. Several methods have been published for the determination of chlordiazepoxide in biological samples such as voltammetry [26], LC [28], and spectrophotometry [29]. In this work, a new reversedphase high-performance liquid chromatographic method is proposed for the simultaneous determination of clidinium bromide and chlordiazepoxide in combined dosage forms. 


\section{Experimental}

2.1. Equipment. A high-performance liquid chromatographic system consisted of Hitachi (Japan) Model L-2000 equipped with a binary pump (model L-2130, flow rate range of $0.000-$ $9.999 \mathrm{~mL} \mathrm{~min}^{-1}$ ), degasser, and a column oven (model L2350 , temperature range of $1-85^{\circ} \mathrm{C}$ ). All samples were injected $(10 \mu \mathrm{L})$ using a Hitachi L-2200 autosampler (injection volume range of $0.1-100 \mu \mathrm{L}$ ). Elutions of all analytes were monitored at $218 \mathrm{~nm}$ by using a Hitachi L-2455 absorbance detector (190-900 nm) containing a quartz flow cell $(10 \mathrm{~mm}$ path and $13 \mu \mathrm{L}$ volume). Each chromatogram was analyzed and integrated automatically using automation system software.

2.2. Materials and Chemicals. Working reference standards of clidinium bromide (CDB), chlordiazepoxide (CDZ), and almotriptan (ALT) were supplied by MSN Laboratories Ltd., Centaur Pharmaceuticals PVT. Ltd., and SMS Pharmaceuticals Ltd., (India), respectively. HPLC grade methanol, acetonitrile, and water were purchased from Labscan (Ireland) and analytical reagent grade ammonium acetate (Merck) was used to prepare the mobile phase. Tablets were purchased from Syrian market, containing clidinium bromide $2.5 \mathrm{mg}$ and chlordiazepoxide $5 \mathrm{mg}$ per tablet.

\subsection{Chromatographic Conditions and Measurement Proce-} dure. Chromatographic separation was performed on a reversed-phase Nucleodur column $\mathrm{C}_{8}(250 \times 4.6 \mathrm{~mm}$ i.d., $5 \mu \mathrm{m}$ particle size) Macherey Nagle (Germany). The mobile phase was a mixture of acetonitrile: methanol:ammonium acetate $(30: 40: 30, \mathrm{v} / \mathrm{v} / \mathrm{v})$. The mobile phase was filtered through a $0.45 \mu \mathrm{m}$ nylon-membrane filter and degassed by ultrasonic agitation prior to use. A flow rate of $1.0 \mathrm{~mL} \mathrm{~min}^{-1}$ was used in order to separate clidinium bromide, chlordiazepoxide and the internal standard almotriptan. The injection volume was $10 \mu \mathrm{L}$. Peak areas were measured and HPLC analysis was conducted at ambient temperature.

2.4. Standard Solutions and Calibration Graphs. Individual stock standard solutions of clidinium bromide $\left(2000.0 \mu \mathrm{g} \mathrm{mL}^{-1}\right)$ and chlordiazepoxide $\left(2000.0 \mu \mathrm{g} \mathrm{mL}^{-1}\right)$ were prepared by dissolving appropriate amounts of pure drugs in methanol in separate brown volumetric flasks. These solutions were stored in the dark under refrigeration at $4^{\circ} \mathrm{C}$ and were found to be stable for ten days. A series of working standard solutions of CDB and CDZ were prepared by the appropriate dilution of the above mentioned stock standard solution in the methanol to reach concentration ranges of $2.5-300.0$ and $3.0-500.0 \mu \mathrm{g} \mathrm{mL}^{-1}$ for CDB and $\mathrm{CDZ}$, respectively. In each sample $100 \mu \mathrm{g} \mathrm{mL}^{-1}$ of the internal standard ALT was added. Working standard solutions were found to be stable during the analysis time.

To construct the calibration curve five replicates $(10 \mu \mathrm{L})$ of each standard solution were injected immediately after preparation into the column and the peak areas of the chromatograms were measured. Then, the mean peak area ratio of $\mathrm{CDB}$ and $\mathrm{CDZ}$ to that of the internal standard was plotted against the corresponding concentration to obtain the calibration graph.
2.5. Tablet (or Capsule) Sample Solutions. Twenty tablets were accurately weighted and finely pulverized. In the case of capsules, the contents of twenty capsules were completely evacuated from shells. An appropriate portion of this powder, equivalent to five tablets content of $\mathrm{CDB}$ and $\mathrm{CDZ}$, was placed in a $25 \mathrm{~mL}$ volumetric flask with $20 \mathrm{~mL}$ of methanol. The solution was sonicated for $15 \mathrm{~min}$ and diluted to volume with methanol to obtain solution of CDB $\left(500 \mu \mathrm{g} \mathrm{mL}^{-1}\right)$ and CDZ $\left(1000 \mu \mathrm{g} \mathrm{mL}^{-1}\right)$. This sample solution was filtered using a $0.45 \mu \mathrm{m}$ nylon filter paper. Consequently a $3 \mathrm{~mL}$ aliquot of this solution was further diluted to $10 \mathrm{~mL}$ methanol containing $100 \mu \mathrm{g} \mathrm{mL}^{-1}$ of the internal standard ALT; $10 \mu \mathrm{L}$ sample was injected into the HPLC system. Peak area ratios of CDB and CDZ to that of the internal standard were then measured for the determinations. These solutions were stored in the dark at $4^{\circ} \mathrm{C}$ and found to be stable for ten days at least.

2.6. Method Validation. The HPLC method was validated in terms of precision, accuracy, and linearity according to ICH guidelines. Assay method precision was determined using five independent test solutions. The intermediate precision of the assay method was also evaluated using different analysts on three different days. For intra day precision, different concentrations of CDB and CDZ were analyzed five times on the same day whereas for inter day precision the same drug concentrations were analyzed on three different days, and the percentage RSD of area was calculated. The accuracy of the assay method was evaluated with the recovery. Linearity test solutions were prepared as described in Section 2.4. Linearity was studied by injecting seven concentrations in replicates of five of the standard $\mathrm{CDB}$ and $\mathrm{CDZ}$ into the HPLC system. The peak area versus concentration data was performed by least-squares linear regression analysis. The limits of detection (LOD) and quantitation (LOQ) values were calculated. To determine the robustness of the method, the final experimental conditions were purposely altered and the results were examined. The flow rate varied by $( \pm)$ $0.1 \mathrm{~mL} \mathrm{~min}^{-1}$, the percentage of organic modifier varied by $( \pm) 5 \%$, and $\mathrm{pH}$ of mobile phase varied by $( \pm) 0.1$.

\section{Results and Discussion}

3.1. Optimization of the Chromatographic Conditions. The optimized compositions were used for the analysis of all solutions individually as well as in combination. The mobile phase used initially was composed of ammonium acetate $(0.1 \mathrm{M})$ and methanol. However, to achieve the optimum resolution, a small portion of acetonitrile was added in the mobile phase until obtaining good results. The chromatographic conditions were optimized for separation of drugs by varying methanol, strength of buffer solution, $\mathrm{pH}$, proportion of acetonitrile, and flow rate. During the optimization of the method, different columns (Nucleodur $\mathrm{C}_{8}, 250 \times 4.6 \mathrm{~mm}$, $5 \mu \mathrm{m}$; Nucleodur $\mathrm{C}_{18} 250 \times 4.6 \mathrm{~mm}, 5 \mu \mathrm{m}$; Hypersil Gold $\mathrm{C}_{8} 250 \times 4.6 \mathrm{~mm}, 5 \mu \mathrm{m}$; ODS Hypersil $\mathrm{C}_{18} 250 \times 4.6 \mathrm{~mm}$, $5 \mu \mathrm{m})$ were tested. The chromatographic separation was achieved on Nucleodur $\mathrm{C}_{8},(250 \times 4.6 \mathrm{~mm}, 5 \mu \mathrm{m})$ column at $25^{\circ} \mathrm{C}$. The peak shape of ALT, CDB, and CDZ was found to be symmetrical. The effect of composition of the mobile 


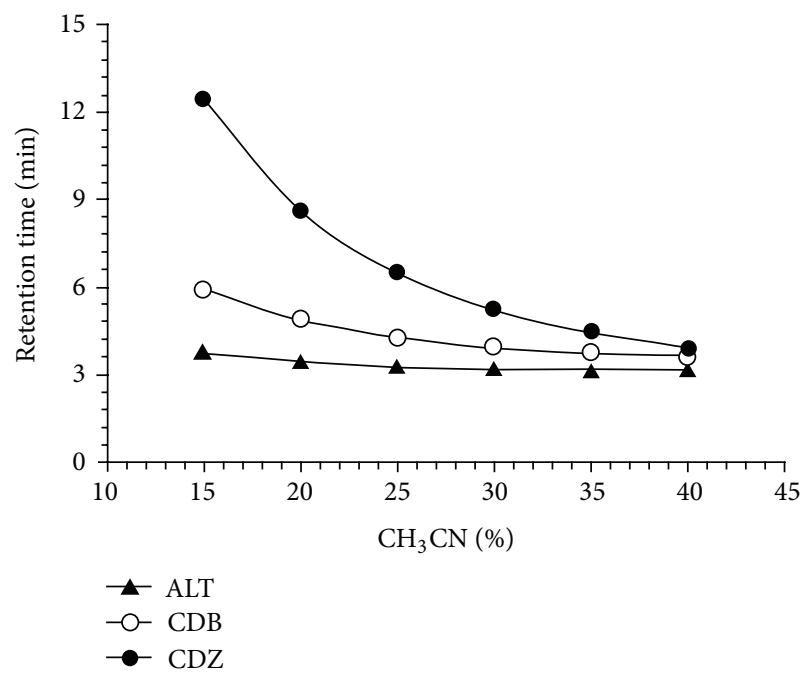

(a)

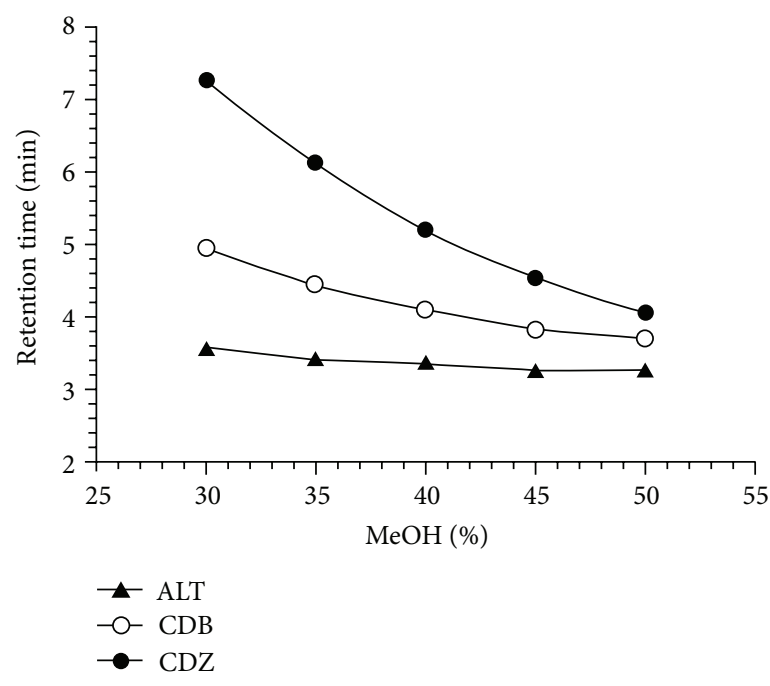

(b)

FIGURE 1: Plots of the retention time versus methanol or acetonitrile percentage in the mobile phase of ALT, CDB, and CDZ.

phase and flow rate on the retention time of ALT, CDB, and $\mathrm{CDZ}$ was investigated. The effect of methanol and acetonitrile percentage in the mobile phase is presented in Figure 1.

An increase in the percentage of methanol and acetonitrile decreases the retention of compounds, ALT, CDB, and CDZ. Increasing methanol percentage to more than $50 \%$ CDB peak is eluted with the solvent front, while at methanol percentage lower than $35 \%$ the elution of CDZ peak is seriously delayed. Also increasing acetonitrile percentage to more than $35 \% \mathrm{CDB}$ peak is eluted with the solvent front, while at acetonitrile percentage lower than $20 \%$ the elution of CDZ peak is seriously delayed. The effect of $\mathrm{pH}$ in the chromatographic elution of the compounds was also investigated by changes the $\mathrm{pH}$ values of the aqueous component of the mobile phase from 4.0 to 6.0. A satisfactory separation and peak asymmetry for the drugs was obtained with mobile phase consisting of ammonium acetate $(0.1 \mathrm{M}, \mathrm{pH} 5.0$ adjusted with acetic acid)-methanol-acetonitrile $(30: 40: 30$, $\mathrm{v} / \mathrm{v} / \mathrm{v}$ ), pumped at a flow rate $1.0 \mathrm{~mL} \mathrm{~min}^{-1}$ at $25^{\circ} \mathrm{C}$. Quantitation was achieved with UV detection at $218 \mathrm{~nm}$ based on peak area. A representative chromatogram is shown in Figure 2. The retention times of ALT, CDB, and CDZ were 3.667, 4.427, and $5.233 \mathrm{~min}$, respectively.

\subsection{Method Validation}

3.2.1. Selectivity. The selectivity of the HPLC method is illustrated in Figure 2 where complete separation of ALT, CDB, and CDZ was noticed. The HPLC chromatogram recorded for the analytes in tablet (Figure 3 ) showed almost no peaks within a retention time range of $15 \mathrm{~min}$. The figures show that $\mathrm{CDB}$ and $\mathrm{CDZ}$ are clearly separated and the peaks of analytes were pure and the excipients in the formulation did not interfere with the analyte. Thus, the HPLC method presented in this study is selective for $\mathrm{CDB}$ and $\mathrm{CDZ}$.

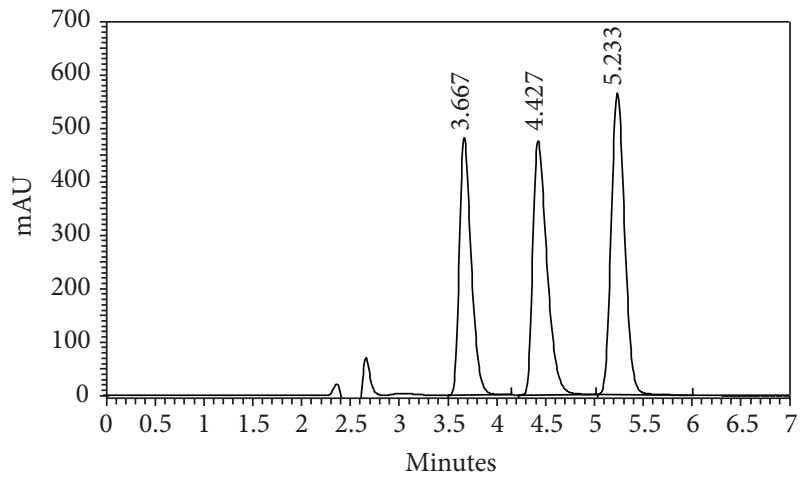

FIgURE 2: A typical chromatogram of a mixture of ALT $\left(100 \mu \mathrm{g} \mathrm{mL}^{-1}\right), \mathrm{CDB}\left(300 \mu \mathrm{g} \mathrm{mL}^{-1}\right)$, and $\mathrm{CDZ}\left(100 \mu \mathrm{g} \mathrm{mL}^{-1}\right)$ at retention times 3.667, 4.427, and $5.233 \mathrm{~min}$, respectively. Chromatographic conditions: RP-HPLC on $\mathrm{C}_{8}$ column; mobile phase: acetonitrile-methanol-ammonium acetate $0.1 \mathrm{M}(30: 40: 30$, v/v/v); flow rate $1.0 \mathrm{~mL} \mathrm{~min}^{-1}$ and detection at $218 \mathrm{~nm}$.

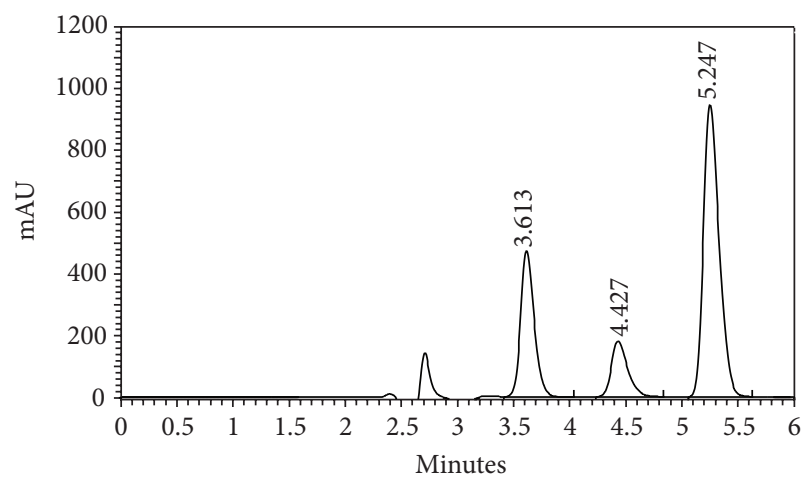

FIgURE 3: A typical chromatogram of a mixture of ALT $\left(100 \mu \mathrm{g} \mathrm{mL}^{-1}\right), \mathrm{CDB}\left(150 \mu \mathrm{g} \mathrm{m}^{-1}\right)$, and $\mathrm{CDZ}\left(300 \mu \mathrm{g} \mathrm{mL}^{-1}\right)$ in the mobile phase, prepared from Laberax tablets. 
TABLE 1: System suitability parameters.

\begin{tabular}{lccc}
\hline Parameter & Almotriptan & Clidinium bromide & Chlordiazepoxide \\
\hline Theoretical plates $(N)$ & 1711 & 4174 & 6598 \\
Resolution factor $^{\mathrm{a}}\left(R_{s}\right)$ & - & 2.59 & 5.19 \\
Tailing factor $(T)$ & 1.03 & 1.43 & 1.16 \\
Capacity factor $(k)$ & 2.19 & 2.90 & 4.20 \\
\% RSD for seven injections & 0.31 & 0.28 & 0.27 \\
\hline
\end{tabular}

${ }^{a}$ The resolution factor is calculated between each peak and its nearest preceding neighbor.

TABLE 2: Sensitivity and regression parameters.

\begin{tabular}{|c|c|c|}
\hline Parameter & Clidinium bromide & Chlordiazepoxide \\
\hline Optimum concentration range $\left(\mu \mathrm{g} \mathrm{mL}^{-1}\right)$ & $2.5-300.0$ & $3.0-500.0$ \\
\hline Regression equation* & $A_{\mathrm{CDB}}=0.4592 C_{\mathrm{CDB}}+1.1366$ & $A_{\mathrm{CDZ}}=1.1895 C_{\mathrm{CDZ}}+2.2553$ \\
\hline Correlation coefficient $(n=5)$ & 0.9999 & 0.9999 \\
\hline Standard deviation of slope & 0.0019 & 0.0025 \\
\hline Standard deviation of intercept & 0.0135 & 0.0504 \\
\hline Regression equation $^{* *}$ & $R_{\mathrm{CDB} / \mathrm{ALT}}=0.003 C_{\mathrm{CDB}}+0.009$ & $R_{\mathrm{CDZ} / \mathrm{ALT}}=0.009 C_{\mathrm{CDZ}}+0.017$ \\
\hline Correlation coefficient $(n=5)$ & 0.9999 & 0.9999 \\
\hline Standard deviation of slope & $1.1 \times 10^{-5}$ & $2.8 \times 10^{-5}$ \\
\hline Standard deviation of intercept & $5.9 \times 10^{-4}$ & $8.1 \times 10^{-4}$ \\
\hline Limit of quantification, LOQ $\left(\mu \mathrm{g} \mathrm{mL}^{-1}\right)$ & 0.294 & 0.403 \\
\hline Limit of detection, $\mathrm{LOD}\left(\mu \mathrm{g} \mathrm{mL}^{-1}\right)$ & 0.088 & 0.121 \\
\hline
\end{tabular}

${ }^{*}$ Regression equation for the peak area of drug versus concentration of drug in $\mu \mathrm{g} \mathrm{mL} L^{-1}$.

${ }^{* *}$ Regression equation for the ratio of peak area of drug to that of I.S. versus concentration of drug in $\mu \mathrm{g} \mathrm{mL}^{-1}$.

3.2.2. System Suitability. In the system suitability tests, five replicate injections of freshly prepared working standard solutions of CDB $\left(300.0 \mu \mathrm{g} \mathrm{mL}^{-1}\right)$ and CDZ $\left(100.0 \mu \mathrm{g} \mathrm{mL}^{-1}\right)$ in the presence of $100.0 \mu \mathrm{g} \mathrm{mL}^{-1}$ of internal standard were injected into the chromatograph, and the theoretical plates, resolution factor, tailing factor, capacity factor, and \% relative standard deviation (\% RSD) of peak areas were determined. The results (Table 1) obtained from system suitability tests are in agreement with the USP requirements. The variation in peak area among five replicate injections of CDB and CDZ standard solutions was very low.

3.2.3. Linearity, Sensitivity, and Limits of Quantification and Detection. The calibration curves for $\mathrm{CDB}$ and $\mathrm{CDZ}$ were linear over the concentration range of $2.5-300.0 \mu \mathrm{g} \mathrm{mL}^{-1}$ and $3.0-500.0 \mu \mathrm{g} \mathrm{mL}^{-1}$, respectively. Correlation coefficients $\left(r^{2}\right)$ of the regression equations were greater than 0.999 . The minimum level at which the investigated compounds can be reliably detected (limit of detection, LOD) and quantified (limit of quantitation, LOQ) was determined experimentally (Table 2). The LOD was expressed as the concentration of drug that generated a response to three times of the signalto-noise $(\mathrm{S} / \mathrm{N})$ ratio, and the LOQ was 10 times of the $\mathrm{S} / \mathrm{N}$ ratio. The $\mathrm{LOD}$ of $\mathrm{CDB}$ and $\mathrm{CDZ}$ attained as defined by IUPAC [30], $\operatorname{LOD}_{(k=3)}=k \times S_{a} / b$ (where $b$ is the slope of the calibration curve and $S_{a}$ is the standard deviation of the intercept), were found to be 0.09 and $0.12 \mu \mathrm{g} \mathrm{mL}^{-1}$, respectively. The LOQ was also attained according to the
IUPAC definition, $\operatorname{LOD}_{(k=10)}=k \times S_{a} / b$, and were found to be 0.32 and $0.40 \mu \mathrm{g} \mathrm{mL}^{-1}$, respectively.

3.2.4. Accuracy and Precision. The precision and accuracy of the method were evaluated by analysis of seven samples for drugs mixture. Intraday assay variation was evaluated by injecting these samples in replicates of five in the same day. Interday assay variation was evaluated by injecting these samples in replicates of five on 4 different days from 1 to 10 days after preparation (Table 3 ). The standard deviation, relative standard deviation, recovery, and relative percentage error of different amounts tested were determined, as recorded in Table 3. The accuracy of the method is indicated by the excellent recovery and the precision is supported by the low standard deviation. Therefore, it was concluded that the procedure gives acceptable accuracy and precision for the analytes.

3.2.5. Robustness. The robustness of an analytical procedure is a measure of its capacity to remain unaffected by small, but deliberate, variations in method parameters and provides an indication of its reliability during normal usage. Robustness of the method was investigated under a variety of conditions including changes of $\mathrm{pH}$ of the mobile phase, flow rate, and percentage of acetonitrile and methanol in the mobile phase. The standard solution is injected in five replicates and sample solution of $100 \%$ concentration is prepared and injected in triplicate for every condition and \% R.S.D. of assay was 
TABLE 3: Accuracy and precision of within- and between-run analysis for the determination of clidinium bromide and chlordiazepoxide by HPLC.

\begin{tabular}{|c|c|c|c|c|c|c|}
\hline \multirow{2}{*}{ Nominal concentration $\left(\mu \mathrm{g} \mathrm{mL}^{-1}\right)$} & \multicolumn{3}{|c|}{ Intra-day $(n=5)$} & \multicolumn{3}{|c|}{ Inter-day $(n=5)$} \\
\hline & $\begin{array}{c}\text { Mean } \pm \\
\mathrm{SD} \mu \mathrm{g} \mathrm{mL}^{-1}\end{array}$ & RSD (\%) & Recovery (\%) & $\begin{array}{c}\text { Mean } \pm \\
\mathrm{SD} \mu \mathrm{g} \mathrm{mL}^{-1}\end{array}$ & RSD (\%) & Recovery (\%) \\
\hline & \multicolumn{6}{|c|}{ Clidinium bromide } \\
\hline 2.50 & $2.52 \pm 0.08$ & 3.17 & 100.80 & $2.51 \pm 0.07$ & 2.79 & 100.40 \\
\hline 6.50 & $6.68 \pm 0.14$ & 2.09 & 102.77 & $6.72 \pm 0.17$ & 2.53 & 103.38 \\
\hline 25.00 & $25.63 \pm 0.51$ & 1.99 & 102.52 & $25.74 \pm 0.28$ & 1.09 & 102.96 \\
\hline 50.00 & $50.86 \pm 0.75$ & 1.47 & 101.72 & $50.61 \pm 0.39$ & 0.77 & 101.22 \\
\hline 75.00 & $75.78 \pm 0.96$ & 1.27 & 101.04 & $76.13 \pm 0.43$ & 0.56 & 101.51 \\
\hline 150.00 & $150.92 \pm 0.91$ & 0.60 & 100.61 & $151.68 \pm 0.75$ & 0.49 & 101.12 \\
\hline \multirow[t]{2}{*}{300.00} & $301.92 \pm 0.44$ & 0.14 & 100.64 & $302.78 \pm 1.73$ & 0.57 & 100.93 \\
\hline & \multicolumn{6}{|c|}{ Chlordiazepoxide } \\
\hline 3.00 & $3.06 \pm 0.09$ & 2.94 & 102.00 & $3.04 \pm 0.08$ & 2.63 & 101.33 \\
\hline 12.00 & $12.13 \pm 0.14$ & 1.15 & 101.08 & $12.10 \pm 0.24$ & 1.98 & 100.83 \\
\hline 25.00 & $25.12 \pm 0.23$ & 0.92 & 100.48 & $25.20 \pm 0.29$ & 1.15 & 100.80 \\
\hline 60.00 & $60.58 \pm 0.54$ & 0.89 & 100.96 & $60.98 \pm 0.58$ & 0.95 & 101.63 \\
\hline 125.00 & $125.05 \pm 0.44$ & 0.35 & 100.04 & $125.42 \pm 0.66$ & 0.53 & 100.34 \\
\hline 250.00 & $250.08 \pm 0.56$ & 0.22 & 100.03 & $249.96 \pm 0.87$ & 0.35 & 99.98 \\
\hline 500.00 & $527.96 \pm 0.97$ & 0.18 & 105.59 & $519.83 \pm 1.09$ & 0.21 & 103.97 \\
\hline
\end{tabular}

TABLE 4: Results of robustness study.

\begin{tabular}{lccccc}
\hline \multirow{2}{*}{ Factor } & \multirow{2}{*}{ Level } & \multicolumn{2}{c}{ Mean \% assay $(n=3)$} & \multicolumn{2}{c}{ \% RSD of results } \\
& & Clidinium bromide & Chlordiazepoxide & Clidinium bromide & Chlordiazepoxide \\
\hline \multirow{2}{*}{ pH of mobile phase } & 5.1 & 100.3 & 100.5 & 1.32 & 0.86 \\
& 4.9 & 100.1 & 100.7 & 0.97 & 0.69 \\
Flow rate (mL/min) & 0.9 & 99.9 & 100.1 & 0.58 & 1.25 \\
\% of acetonitrile & 1.1 & 100.2 & 100.8 & 0.47 & 0.53 \\
& 25 & 99.7 & 101.05 & 0.04 & 0.96 \\
\% of methanol & 35 & 100.6 & 100.6 & 0.73 & 0.49 \\
\hline
\end{tabular}

calculated for each condition. The degree of reproducibility of the results obtained as a result of small deliberate variations in the method parameters has proven that the method is robust (Table 4).

3.2.6. Stability Studies. Stability studies were carried out at laboratory temperature for 10 days to find potential stability problems of the drug in the formulations. Samples were analyzed at intervals of $0,1,5$, and 10 days. The results obtained are given in Table 5. The percent RSD values between subsequent readings gave an indication of the stability of the drug in the formulations.

3.3. Application of the Assay. The developed method was successfully applied to analyze CDB and CDZ in marketed tablet formulations. The assay results are shown below for the average of five determinations of the four tablets. The performance of the proposed methods was assessed by comparison with the official method [8]. Mean values were obtained with Student's $t$ - and F-tests at 95\% confidence limits for four degrees of freedom. The results showed comparable accuracy $(t$-test) and precision $(F$-test), since the calculated values of $t$ and $F$-tests were less than the theoretical data. The proposed procedures were applied to determine CDB and CDZ in their pharmaceutical formulations (Figure 3 ). The results in Table 6 indicate the high accuracy and precision. As can be seen from Table 6 , the proposed methods have the advantages of being virtually free from interferences by excipients such as glucose, lactose, and starch or from common degradation products. The results obtained were compared statistically by the Student's $t$-test (for accuracy) and the variance ratio $F$-test (for precision) with those obtained by the official method for the samples of the same batch (Table 6). The values of $t$ - and $F$-tests obtained at 95\% confidence level did not exceed the theoretical tabulated values indicating no significant difference between the methods compared. 
TABLE 5: Stability study for the drug in different formulations.

\begin{tabular}{|c|c|c|c|c|c|c|c|}
\hline \multirow{2}{*}{ Product $^{\mathrm{a}}$} & \multirow{2}{*}{ Time (days) } & \multicolumn{2}{|c|}{ Amount found $^{\mathrm{b}}(\mathrm{mg})$} & \multicolumn{2}{|c|}{ \% Recovery } & \multicolumn{2}{|c|}{$\% \pm \mathrm{RSD}$} \\
\hline & & $\mathrm{CDB}$ & $\mathrm{CDZ}$ & $\mathrm{CDB}$ & $\mathrm{CDZ}$ & $\mathrm{CDB}$ & $\mathrm{CDZ}$ \\
\hline \multirow{4}{*}{ Ribax capsules } & 0 & 2.51 & 5.04 & 100.40 & 100.80 & 1.91 & 0.22 \\
\hline & 1 & 2.52 & 5.05 & 100.80 & 101.00 & 0.98 & 0.49 \\
\hline & 5 & 2.50 & 5.02 & 100.00 & 100.40 & 0.32 & 0.74 \\
\hline & 10 & 2.49 & 5.01 & 99.60 & 100.20 & 1.05 & 0.86 \\
\hline \multirow{4}{*}{ Laberax tablets } & 0 & 2.56 & 5.03 & 102.40 & 100.60 & 0.49 & 0.29 \\
\hline & 1 & 2.55 & 5.05 & 102.00 & 101.00 & 0.53 & 0.36 \\
\hline & 5 & 2.51 & 5.04 & 100.40 & 100.80 & 0.82 & 0.40 \\
\hline & 10 & 2.52 & 5.01 & 101.80 & 100.20 & 0.75 & 0.29 \\
\hline \multirow{4}{*}{ Librax tablets } & 0 & 2.58 & 5.01 & 103.20 & 100.20 & 1.13 & 0.31 \\
\hline & 1 & 2.55 & 5.00 & 102.00 & 100.00 & 0.97 & 0.91 \\
\hline & 5 & 2.53 & 4.99 & 101.20 & 99.80 & 0.68 & 0.87 \\
\hline & 10 & 2.54 & 4.98 & 101.60 & 99.60 & 0.81 & 0.95 \\
\hline
\end{tabular}

${ }^{\mathrm{a}}$ The dose is $2.5 \mathrm{mg} \mathrm{CDB}$ and $5.0 \mathrm{mg} \mathrm{CDZ}$ for all products.

${ }^{\mathrm{b}}$ Five independent analyses.

TABLE 6: Determination of CDB and CDZ in pharmaceutical formulations by the proposed method and official method.

\begin{tabular}{|c|c|c|c|c|}
\hline \multirow{3}{*}{ Sample } & \multicolumn{2}{|c|}{ Clidinium bromide } & \multicolumn{2}{|c|}{ Chlordiazepoxide } \\
\hline & \multicolumn{4}{|c|}{$\%$ Recovery $^{\mathrm{a}} \pm$ S.D. } \\
\hline & Proposed method & Official method & Proposed method & Official method \\
\hline \multicolumn{5}{|c|}{ Ribax (2.5 mg CDB and 5.0 mg CDZ/capsule) } \\
\hline$X \pm$ S.D. ${ }^{\mathrm{a}}$ & $100.49 \pm 1.92$ & $100.97 \pm 1.58$ & $100.89 \pm 0.22$ & $100.04 \pm 0.17$ \\
\hline$t$-value ${ }^{\mathrm{b}}$ & 1.96 & 2.03 & 2.12 & 1.89 \\
\hline$F$-value ${ }^{\mathrm{b}}$ & 1.47 & & 1.67 & \\
\hline \multicolumn{5}{|c|}{ Laberax (2.5 mg CDB and $5.0 \mathrm{mg}$ CDZ/tablet) } \\
\hline$X \pm$ S.D. ${ }^{\mathrm{a}}$ & $102.58 \pm 0.51$ & $101.33 \pm 0.42$ & $100.59 \pm 0.30$ & $99.85 \pm 0.23$ \\
\hline$t$-value ${ }^{\mathrm{b}}$ & 1.28 & 1.92 & 1.73 & 1.83 \\
\hline$F$-value ${ }^{\mathrm{b}}$ & 1.47 & & 1.70 & \\
\hline \multicolumn{5}{|c|}{ Librax (2.5 mg CDB and 5.0 mg CDZ/tablet) } \\
\hline$X \pm$ S.D. ${ }^{\mathrm{a}}$ & $103.45 \pm 1.17$ & $102.06 \pm 1.08$ & $100.25 \pm 0.31$ & $100.12 \pm 0.28$ \\
\hline$t$-value $\mathrm{e}^{\mathrm{b}}$ & 2.04 & 2.18 & 1.60 & 1.74 \\
\hline$F$-value ${ }^{\mathrm{b}}$ & 1.17 & & 1.23 & \\
\hline
\end{tabular}

Five independent analyses.

${ }^{\mathrm{b}}$ Theoretical values for $t$ and $F$-values at five degree of freedom and 95\% confidence limit are $(t=2.776)$ and $(F=6.26)$.

\section{Conclusion}

A simple, specific, precise, and sensitive RP-HPLC method has been developed and validated for quantitative determination of clidinium bromide and chlordiazepoxide in raw materials and pharmaceutical preparations with a limit of detection of 0.088 and $0.121 \mu \mathrm{g} \mathrm{mL}^{-1}$ for CDB and CDZ, respectively. The sample recoveries from all formulations were in good agreement with their respective label claims, which suggested noninterference of formulation excipients in the estimation. The developed method has more speed and higher sensitivity as compared to sophisticated spectrophotometric techniques and similar reported methods and has a wider range of linearity. Moreover, the lower solvent consumption along with the short analytical run time of 6.0 min leads to an environmentally friendly chromatographic procedure, which makes it especially suitable for routine quality control analysis work.

\section{Conflict of Interests}

There is no kind of financial gain between the authors and the mentioned corporations and identities inside the paper.

\section{References}

[1] G. K. Mcevory, Ed., AHFS Drug Information, American Society of Hospital Pharmacists, 1990.

[2] J. Gasparic and J. Zimak, "Analysis of the 1, 4-benzodiazepines by methods based on hydrolysis," Journal of Pharmaceutical and Biomedical Analysis, vol. 1, no. 3, pp. 259-279, 1983.

[3] B. C. Rudy and B. Z. Senkowski, "Clidinium Bromide," in Analytical Profiles of Drug Substances, K. Florey, Ed., vol. 2, pp. 145161, Academic Press, New York, NY, USA, 1973.

[4] United States Pharmacopoeia, United States Pharmacopoeia Convention, Rockville, Md, USA, 34th edition, 2011.

[5] A. Pathak, P. Rai, and S. J. Rajput, "Stability-indicating HPLC method for simultaneous determination of clidinium bromide 
and chlordiazepoxide in combined dosage forms," Journal of Chromatographic Science, vol. 48, no. 3, pp. 235-239, 2010.

[6] S. M. Yuen and G. Lehr, "Liquid chromatographic determination of clidinium bromide and clidinium bromide-chlordiazepoxide hydrochloride combinations in capsules," Journal of the Association of Official Analytical Chemists, vol. 74, no. 3, pp. 461464, 1991.

[7] I. M. Jalal, S. I. Sa'sa, A. Hussein, and H. S. Khalil, "Reversephase high-performance liquid chromatographic determination of clidinium bromide and chlordiazepoxide in tablet formulations," Analytical Letters, vol. 20, no. 4, pp. 635-655, 1987.

[8] M. I. Toral, P. Richter, N. Lara, P. Jaque, C. Soto, and M. Saavedra, "Simultaneous determination of chlordiazepoxide and clidinium bromide in pharmaceutical formulations by derivative spectrophotometry," International Journal of Pharmaceutics, vol. 189, no. 1, pp. 67-74, 1999.

[9] S. A. Özkan, N. Erk, and Z. Sentürk, "Simultaneous determination of two-component mixtures in pharmaceutical formulations containing chlordiazepoxide by ratio spectra derivative spectrophotometry," Analytical Letters, vol. 32, no. 3, pp. 497520, 1999.

[10] M. R. Khoshayand, H. Abdollahi, A. Moeini, A. Shamsaie, A. Ghaffari, and S. Abbasian, "Simultaneous spectrophotometric determination of chlordiazepoxide and clidinium using multivariate calibration techniques," Drug Testing and Analysis, vol. 2, no. 9, pp. 430-435, 2010.

[11] N. K. Jagota and J. T. Stewart, "Separation of chlordiazepoxide and selected chlordiazepoxide mixtures using capillary SFC," Journal of Liquid Chromatography, vol. 16, no. 2, pp. 291-305, 1993.

[12] B. Nickerson, "The determination of a degradation product in clidinium bromide drug substance by capillary electrophoresis with indirect UV detection," Journal of Pharmaceutical and Biomedical Analysis, vol. 15, no. 7, pp. 965-971, 1997.

[13] A. Sheibani, M. R. Shishehbore, and Z. T. Ardakani, "Kinetic spectrophotometric determination of bromide in clidinium-c drug," Chinese Chemical Letters, vol. 22, no. 5, pp. 595-598, 2011.

[14] S. E. Roberts and M. F. Delaney, "Determination of chlordiazepoxide, its hydrochloride and related impurities in pharmaceutical formulations by reversed-phase high-performance liquid chromatography," Journal of Chromatography, vol. 283, pp. 265$272,1984$.

[15] J. B. Zagar, F. J. Van Lenten, and G. P. Chrekian, "High pressure liquid chromatographic separation and quantitation of chlordiazepoxide. $\mathrm{HCl}$ and two of its related compounds," Journal of the Association of Official Analytical Chemists, vol. 61, no. 3, pp. 678-682, 1978.

[16] D. Burke and H. Sokoloff, "Simultaneous high-performance liquid chromatographic determination of chlordiazepoxide and amitriptyline hydrochloride in two-component tablet formulations," Journal of Pharmaceutical Sciences, vol. 69, no. 2, pp. 138140, 1980.

[17] R. T. Sane, D. P. Gangal, R. V. Tendolkar, R. M. Kothurkar, and K. D. Ladage, "Simultaneous high performance liquid chromatographic determination of amitriptyline hydrochloride and chlordiazepoxide from pharmaceutical preparations," Indian Journal of Pharmaceutical Sciences, vol. 51, no. 2, pp. 68-70, 1989.

[18] M. A. Abuirjeie and M. E. Abdel-Hamid, "Simultaneous highperformance liquid chromatographic and first-derivative spectrophotometric determination of amitriptyline hydrochloride and chlordiazepoxide in capsules," Analytical Letters, vol. 22, no. 4, pp. 951-962, 1989.
[19] R. S. Haggag, R. A. Shaalan, and T. S. Belal, "Validated HPLC determination of the two fixed dose combinations (chlordiazepoxide hydrochloride and mebeverine hydrochloride; carvedilol and hydrochlorothiazide) in their tablets," Journal of AOAC International, vol. 93, no. 4, pp. 1192-1200, 2010.

[20] S. K. Patel and N. J. Patel, "Simultaneous RP-HPLC estimation of trifluoperazine hydrochloride and chlordiazepoxide in tablet dosage forms," Indian Journal of Pharmaceutical Sciences, vol. 71, no. 5, pp. 545-547, 2009.

[21] B. Q. Che, "Determination of five components in compound hypotensive tablet by HPLC," Yaoxue Xuebao, vol. 39, no. 8, pp. 618-620, 2004.

[22] A. Zevzikoviene, A. Zevzikovas, and A. Bertulis, "Determination of diazepine derivatives: alprazolam, medazepam, chlordiazepoxid mixture by high performance liquid chromatography," Medicina, vol. 39, pp. 37-41, 2003.

[23] S. K. Patel and N. J. Patel, "Simultaneous determination of imipramine hydrochloride and chlordiazepoxide in pharmaceutical preparations by spectrophotometric, rp-hplc, and hptlc methods," Journal of AOAC International, vol. 93, no. 3, pp. 904910, 2010.

[24] M. I. Walash, M. Rizk, and A. El-Brashy, "Spectrophotometric determination of chlordiazepoxide and nitrazepam," Talanta, vol. 35, no. 11, pp. 895-898, 1988.

[25] D. J. White, J. T. Stewart, and I. L. Honigberg, "Quantitative analysis of chlordiazepoxide hydrochloride and related compounds in drug substance and tablet dosage form by HPTLC and scanning densitometry," Journal of Planar Chromatography Modern, vol. 4, no. 4, pp. 330-332, 1991.

[26] G. B. El-Hefnawey, I. S. El-Hallag, E. M. Ghoneim, and M. M. Ghoneim, "Voltammetric behavior and quantification of the sedative-hypnotic drug chlordiazepoxide in bulk form, pharmaceutical formulation and human serum at a mercury electrode," Journal of Pharmaceutical and Biomedical Analysis, vol. 34, no. 1, pp. 75-86, 2004.

[27] Y. M. Issa, N. T. Abdel-Ghani, A. F. Shoukry, and H. M. Ahmed, "New conventional coated-wire ion-selective electrodes for flow-injection potentiometric determination of chlordiazepoxide," Analytical Sciences, vol. 21, no. 9, pp. 1037-1042, 2005.

[28] D. J. Garretty, K. Wolff, and A. W. M. Hay, "Micro-extraction of chlordiazepoxide and its primary metabolites, desmethylchlordiazepoxide and demoxepam, from plasma and their measurement by liquid chromatography," Annals of Clinical Biochemistry, vol. 35, no. 4, pp. 528-533, 1998.

[29] J. H. Riddick, "An ultraviolet and visible spectrophotometric assay method for chlordiazepoxide," Clinical Biochemistry, vol. 6, no. 3, pp. 189-199, 1973.

[30] G. L. Long and J. D. Winefordner, "Limit of detection: a closer look at the IUPAC definition," Analytical Chemistry A, vol. 55, no. 7, pp. 712-724, 1983. 

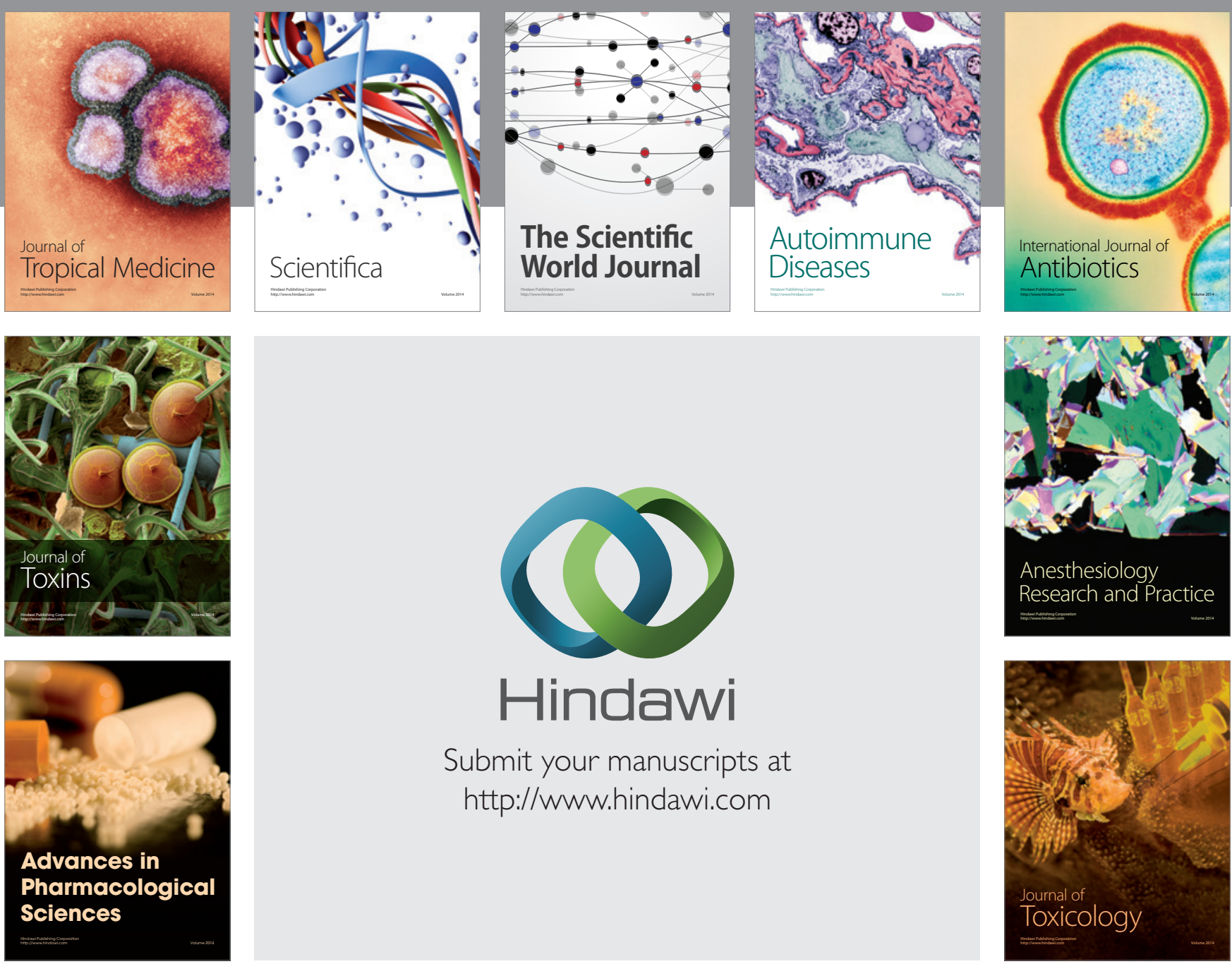

\section{Hindawi}

Submit your manuscripts at

http://www.hindawi.com
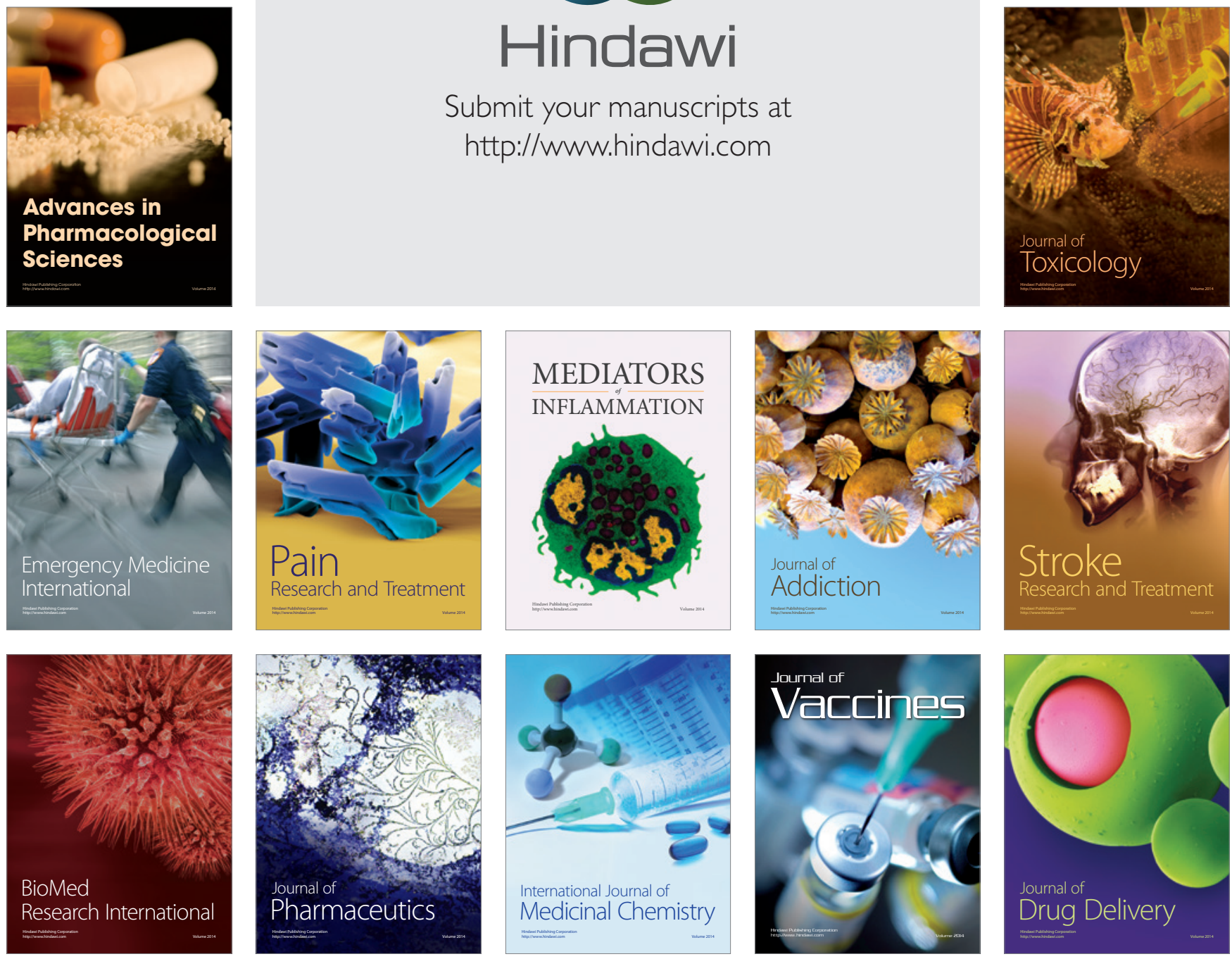